\title{
Diphtheria outbreak in Yemen: the impact of conflict on a fragile health system
}

\author{
Fekri Dureab ${ }^{1 *} \mathbb{D}$, Maysoon Al-Sakkaf ${ }^{2}$, Osan Ismail ${ }^{2}$, Naasegnibe Kuunibe ${ }^{1,3}$, Johannes Krisam ${ }^{4}$, Olaf Müller ${ }^{1}$ and
} Albrecht Jahn'

\begin{abstract}
Background: War in Yemen started three years ago, and continues unabated with a steadily rising number of direct and indirect victims thus leaving the majority of Yemen's population in dire need of humanitarian assistance. The conflict adversely affects basic socioeconomic and health conditions across the country.

Methods: This study analyzed the recent ongoing diphtheria outbreak in Yemen and in particular, the health system's failure to ensure immunization coverage and respond to this outbreak. Data from the weekly bulletins of the national electronic Disease Early Warning System's (eDEWS) daily diphtheria reports and district immunization coverage were analyzed. The number of diphtheria cases and deaths, and immunization coverage (DPT) were reviewed by district including the degree to which a district was affected by conflict using a simple scoring system. A logistic regression and bivariate correlation were applied using the annual immunization coverage per district to determine if there was an association between diphtheria, immunization coverage and conflict.
\end{abstract}

Results: The study results confirm the association between the increasing cases of diphtheria, immunization coverage and ongoing conflict. A total of 1294 probable cases of diphtheria were reported from 177 districts with an overall case fatality rate of $5.6 \%$. Approximately $65 \%$ of the patients were children under 15 years, and $46 \%$ of the cases had never been vaccinated against diphtheria. The risk of an outbreak increased by 11-fold if the district was experiencing ongoing conflict $p<0.05$. In the presence of conflict (whether past or ongoing), the risk of an outbreak decreased by 0.98 if immunization coverage was high $p>0.05$.

Conclusion: The conflict is continuously devastating the health system in Yemen with serious consequences on morbidity and mortality. Therefore, the humanitarian response should focus on strengthening health services including routine immunization procedures to avoid further outbreaks of life-threatening infectious diseases, such as diphtheria.

Keywords: Diphtheria outbreak, Immunization, Conflict, Yemen

\section{Introduction}

Diphtheria is a life-threatening bacterial disease caused by Corynebacterium diphtheria, a non-encapsulated gram-positive bacillus. It is transmitted through close respiratory contact, causes airway obstruction due to nasopharyngeal infection, and may spread to other organs [1-3].

Diphtheria is a vaccine-preventable disease, which was largely eliminated in industrialized countries decades

\footnotetext{
* Correspondence: fekridureab@yahoo.com

${ }^{1}$ Heidelberg Institute of Global Health, Hospital University- Heidelberg,

Heidelberg, Germany

Full list of author information is available at the end of the article
}

ago. In low-income countries, diphtheria control was much improved by global efforts, such as the Expanded Program on Immunization (EPI) in the second half of the twentieth century [4]. However, diphtheria reemerged during the 1990s in a number of countries In Europe, triggered by the breakdown of health services across the former Soviet Union $[2,5]$.

Diphtheria remains a problem in a number of low-income countries with poor immunization coverage. Several outbreaks have been reported in sub-Saharan Africa (e.g. Nigeria and Madagascar) since 2000 [6]. Bangladesh experienced recently an outbreak in a large refugee camp for the Rohinga in 2017 [7].

(c) The Author(s). 2019 Open Access This article is distributed under the terms of the Creative Commons Attribution 4.0 International License (http://creativecommons.org/licenses/by/4.0/), which permits unrestricted use, distribution, and 
Currently, India, Indonesia and Nepal have the highest number of diphtheria cases in Asia [6].

Even in countries with rather good immunization coverage, such as Thailand and Iran, outbreaks of 157 and 513 cases respectively, have occurred in recent years [6]. Since the last major outbreaks of diphtheria in the 1990s, cases continue to be reported from Europe as well. In 2014, for example, 22 cases of confirmed diphtheria were reported in the European Union, and about half of these cases were in Latvia [8].

Yemen had experienced no serious diphtheria outbreaks until very recently. From October 2017 to August 2018, 2203 probable diphtheria cases (including 116 deaths) were reported. Unfortunately, few diphtheria case alerts were generated prior to the declaration of an outbreak by the electronic surveillance system [9]. Yemen has been engaged in civil war since March 2015, which has severely affected the country's infrastructure including health services. Less than $50 \%$ of existing health facilities are fully functional and there is a serious shortage of staff, medicine and equipment [10]. The conflict has led to major population movements, increased direct morbidity and mortality, and indirect adverse effects on the population due to dysfunctional services and a lack of food, clean water, and sanitation [11]. One consequence has been a significant cholera epidemic since 2016 [12-14].

Yemen is in the southwest of the Arabian Peninsula, bordered by Saudi Arabia to the north and Oman to the east and surrounded by water to the south and west [15]. The country is administratively divided into 22 governorates and 333 districts. It is a low-income country with high poverty and illiteracy rates [16]. The country has experienced many crises since 2011, which began with the Arab Spring's efforts against poverty, unemployment, corruption, and political instability. The political situation moved into a new complicated stage in March 2015 with the beginning of civil war [17], which has led to the country's fragmentation into multiple semi-autonomous entities running basic services $[18,19]$.

The health systems include four levels of health facilities: health units, health centers, district or governorate hospitals, and referral hospitals [20]. There are approximately 4207 public health facilities including 243 hospitals [21]. Approximately 16.4 million have no access to basic healthcare [22], and only $43 \%$ of the functional health facilities have communicable diseases services. Maternal and new-born services including immunization services are available in only $35 \%$ of functional health facilities [23]. Diphtheria outbreaks reflect a huge gap in the immunization coverage in the last three years due to the obviously collapsed health system in Yemen. A recent $\mathrm{WHO}$ report shows that the coverage for vaccination against diphtheria/pertussis/tetanus 1 (DPT1) coverage shrank gradually over the last three years: approximately 89,88 and $83 \%$ in 2015, 2016 and 2017 respectively [24, 25]. This paper describes the recent diphtheria outbreak and explains the relationship between diphtheria cases, immunization and conflict dynamics in Yemen.

\section{Methods}

\section{Data sources}

We used multiple national-level data sources to describe and analyze the recent diphtheria outbreak in Yemen. First, data from the weekly bulletins of the electronic Disease Early Warning System (eDEWS) (1st epidemiological week of 2017 to the 10th epidemiological week of 2018) were used to identify the trend of the diphtheria outbreak. The second data source was the daily diphtheria surveillance reports on district and governorate levels. The third source was the 2017 annual immunization coverage report from 333 Yemeni districts. Finally, the 2017 report on the level of conflict was analyzed after districts were categorized according to conflict dynamic: $1=$ experience ongoing armed conflict (65 districts), $2=$ history of past armed conflict (48 districts), and $3=$ no conflict (219 districts). The primary outcome, "diphtheria outbreak" (yes/no) was determined for each district by assessing the presence of diphtheria cases within a district. If there was at least one case of diphtheria in a particular district, this was considered as an outbreak.

\section{Diphtheria case definitions [26]}

Clinical description An illness characterized by laryngitis or pharyngitis or tonsillitis, and an adherent membrane of the tonsils, pharynx and/or nose.

Laboratory criteria for diagnosis Isolation of Corynebacterium diphtheriae from a clinical specimen, or fourfold or greater rise in serum antibody (but, only if both serum samples were obtained before the administration of diphtheria toxoid or antitoxin).

Case classification Suspected: Not applicable.

Probable: A case that meets the clinical description.

Confirmed: A probable case that is laboratory confirmed or linked epidemiologically to a laboratory confirmed case.

\section{Data analyses}

We describe the trend of diphtheria cases between the 1st week of 2017 to the 10th week of 2018 in Yemen based on data obtained from the weekly epidemiological eDEWS Bulletin. To determine the relationship between the outbreak, immunization and conflict dynamics, we regressed conflict dynamic on immunization on diphtheria 
for all districts in 2017, whether or not the district had experienced conflict in the past year, was currently experiencing armed conflict, or had never experienced armed conflict. We tested for an interaction between immunization and past armed conflict (imcoconf1) and between immunization and current armed conflict (imcoconf2).

Given that the outcome variable (diphtheria outbreak denoted as dipht) was binary, we used the binary logit regression [27]. Following applications in health research [28], we specified the model as

$$
L=\ln \left(\frac{P_{i}}{1-P_{i}}\right)=\forall+X \beta+\epsilon
$$

where $\operatorname{in}\left(\frac{P_{i}}{1-P_{i}}\right)$ is the natural logarithm of the ratio of the probability that a diphtheria outbreak will occur in a location given the explanatory variables of the respective district $\left(\mathrm{P}_{-} \mathrm{i}=\mathrm{P}\left[\mathrm{dipht}=1 \mid \mathrm{X} \_\mathrm{i}\right]\right)$ divided by the probability that an outbreak will not occur (1-P_i), and $\forall$ is a constant term, $X$ is a vector of explanatory variables, $\beta$ is a vector of coefficients and $\epsilon$ is the random error term. Table 1 presents the definitions of all variables.

We estimated the eq. (2) and calculated the odd ratios (OR) to compare the relative odds of a diphtheria outbreak with the given conflict dynamics while controlling for number of immunized children in the district.

$$
\begin{aligned}
\ln \left(\frac{P_{i}}{1-P_{i}}\right)= & \forall+\beta_{1} \text { imco }+\beta_{2} \text { confhis } 0 \\
& +\beta_{3} \text { confhis } 1+\beta_{4} \text { confhis } 2 \\
& +\beta_{5} \text { imcoconf } 1+\beta_{6} \text { imcoconf } 2 \\
& +\epsilon
\end{aligned}
$$

$\mathrm{OR}=1$ means the particular conflict dynamic does not affect the odds of a diphtheria outbreak, OR $>1$ means a particular conflict dynamic is associated with higher odds of a diphtheria outbreak, and $\mathrm{OR}<1$ means a particular conflict dynamic is associated with lower odds of a diphtheria outbreak. The variable confhis 0 serves as base category for confhis 1 and confhis 2 and so does not enter the model. A $p$-value smaller than 0.05 was regarded as statistically significant. Analyses were conducted using the software Stata version 15.

\section{Results}

A diphtheria outbreak was announced on 29 October 2017 by the Ministry of public Health and population and WHO in Yemen. From that date to March 10, 2018, a total of 1294 probable cases were recorded in 177/333 (53\%) districts in 20/23 (87\%) governorates. Table 2 presents the distribution of reported cases, deaths and corresponding case fatality rate (CFR) by governorates. Most cases occurred in three governorates, Ibb governorate (441cases, 34\%), Hodeida governorate (151 cases, $12 \%)$ and Sana'a governorate (133 cases, 10\%). A total of 73 deaths were reported in all governorates, which resulted in an overall CFR of $5.6 \%$.

Figure 1 shows the trend in reported number of probable diphtheria cases and alerts generated by eDEWS, from epidemiological week 39 in 2017 to week 10 in 2018. The trend shows a gradual increase in diphtheria cases reaching a peak in epidemiological week 4 in 2018 (102 cases/week; reported by 14 governorates). The trend then shows a gradual decline in the number of cases.

Table 3 shows the distribution of diphtheria cases and deaths and corresponding CFRs by age, sex and vaccination status. Diphtheria morbidity and mortality did not significantly differ between males and females and the majority of cases occurred in children and adolescents who also had the highest CFRs ( $11 \%$ in children under 5 years old, but only approximately $1 \%$ in those $35-50$ years old). Diphtheria vaccination status was strongly and inversely associated with CFRs. However, although $31 \%$ of diphtheria cases were people reported to have taken three doses of diphtheria vaccination, their CFR was only $2.9 \%$.

\section{Relationship between conflict and diphtheria outbreak}

Table 4 shows the results from the bivariate logistic regression analysis. To explore the relationship between the conflict situation in Yemen and the diphtheria outbreak, we regressed the outcome variable (whether a district experienced outbreak or not as diphtheria outbreak $=1$, no outbreak $=0$ ) with the conflict dynamic in the district. The bivariate regression results show that immunization generally does affect the probability of

Table 1 Measurement of variables for analysis of diphtheria, conflict and immunization status

\begin{tabular}{llr}
\hline Variable & Definition & Measurement \\
\hline dipth & Diphtheria outbreak in district & $1=$ yes; 0=no \\
imco & Immunized children in district (\# immunized children-less than 1 year old in 2017) & Continuous \\
confhis1 & District experienced conflict in the past (more than 3 years) & $1=$ yes; 0=no \\
confhis2 & District currently experiencing conflict & $1=y e s ; 0=n o$ \\
imcoconf1 & Immunized children in district with past conflict (imco x conf his1) & $>0$ \\
imcoconf2 & Immunized children in district with current conflict & $>0$ \\
& (imco $x$ conf his2) & \\
\hline
\end{tabular}


Table 2 Distribution of diphtheria cases, deaths and corresponding case fatality rates by governorates in Yemen (October 2017 March 2018)

\begin{tabular}{|c|c|c|c|c|c|}
\hline Governorates & Total No. of districts & No of affected districts & No of probable cases & Deaths & CFR (\%) \\
\hline lbb & 20 & 19 & 441 & 16 & 3.6 \\
\hline Abyan & 11 & 1 & 4 & 2 & 50.0 \\
\hline Sana'a city & 10 & 9 & 60 & 1 & 1.7 \\
\hline Al Baidha & 20 & 11 & 19 & 3 & 15.8 \\
\hline Al Jawf & 12 & 3 & 6 & 3 & 50.0 \\
\hline Al Hodeida & 26 & 20 & 151 & 12 & 7.9 \\
\hline Ad Dhale’a & 9 & 8 & 107 & 2 & 1.9 \\
\hline Al Mahweet & 9 & 8 & 52 & 1 & 1.9 \\
\hline Al Mahrah & 9 & 0 & 0 & 0 & \\
\hline Taiz & 23 & 15 & 45 & 6 & 13.3 \\
\hline Hajjah & 31 & 15 & 48 & 4 & 8.3 \\
\hline Al Mukalla & 12 & 0 & 0 & 0 & \\
\hline Say'on & 16 & 2 & 2 & 0 & 0.0 \\
\hline Damar & 12 & 9 & 39 & 4 & 10.3 \\
\hline Raymah & 6 & 3 & 6 & 2 & 33.3 \\
\hline Socotra & 2 & 0 & 0 & 0 & \\
\hline Shabwah & 17 & 1 & 1 & 0 & 0.0 \\
\hline Sadah & 15 & 4 & 11 & 3 & 27.3 \\
\hline Sana'a & 16 & 15 & 133 & 5 & 3.8 \\
\hline Aden & 8 & 7 & 63 & 2 & 3.2 \\
\hline Amran & 20 & 19 & 86 & 4 & 4.7 \\
\hline Lahj & 15 & 5 & 10 & 2 & 20.0 \\
\hline Mareb & 14 & 3 & 10 & 1 & 10.0 \\
\hline Total & 333 & 177 & 1294 & 73 & $5.6 \%$ \\
\hline
\end{tabular}

diphtheria outbreak $(\mathrm{OR}=1.02 ; \mathrm{CI}=1.01-1.03, p<0.05)$. The same was observed for the effects of immunization in areas where conflict was ongoing $(\mathrm{OR}=1.01 ; \mathrm{CI}=$ $1.004-1.016, p<0.05)$. However, the probability of an outbreak increased significantly in areas where conflict was ongoing $(\mathrm{OR}=1.89 ; \mathrm{CI}=1.20-2.99, p<0.05)$. From the multivariate regression results, immunization did affect the risk of an outbreak $(\mathrm{OR}=1.04$; $\mathrm{CI}=1.012$ $1.058, p<0.05)$. This is to say, that in a district without conflict, immunization had a minimal effect on the diphtheria outbreak situation. The odds of an outbreak significantly increased 11 -fold if the district was experiencing ongoing conflict $(\mathrm{OR}=11.21$; $\mathrm{CI}=1.29$ 97.69, $p<0.05$ ) and 3 -fold if the district had had a history of conflict in the past year (although not statistically significant) see Table 5 .

\section{Discussion}

The number of cases detected weekly by eDEWS revealed that a number of diphtheria alerts had already been detected in 2017, starting in epidemiological week 5. An official statement of the Ministry of Public Health and Population (MOPHP) on the outbreak was only launched in epidemiological week 39. This gap can be explained by the intensity of the current war that delays the timeliness of reporting and response and increases the inaccessibility to basic services [14]. Children under 15 years were the most affected during this diphtheria outbreak (65\%) compared to those in older age groups. For comparison, a similar study in Lao People's Democratic Republic (Laos), in 2016, revealed that $69 \%$ of diphtheria cases were among children under 15 years [29]. The overall diphtheria CFR in Yemen has been $5.6 \%$, and was highest among under-five children (11\%). Likewise, during the recent diphtheria outbreak among the Rohingya refugee in Bangladesh, 13\% of affected cases were children under five [30].

In our study, $46 \%$ of diphtheria cases and $69 \%$ of deaths were among the unvaccinated group. This corresponds to findings from a case-control study in Laos where approximately $34 \%$ of the people with diphtheria had not received any DPT doses [29,31].

This study revealed the relationship between conflict and the diphtheria outbreak in Yemen, showing that the 


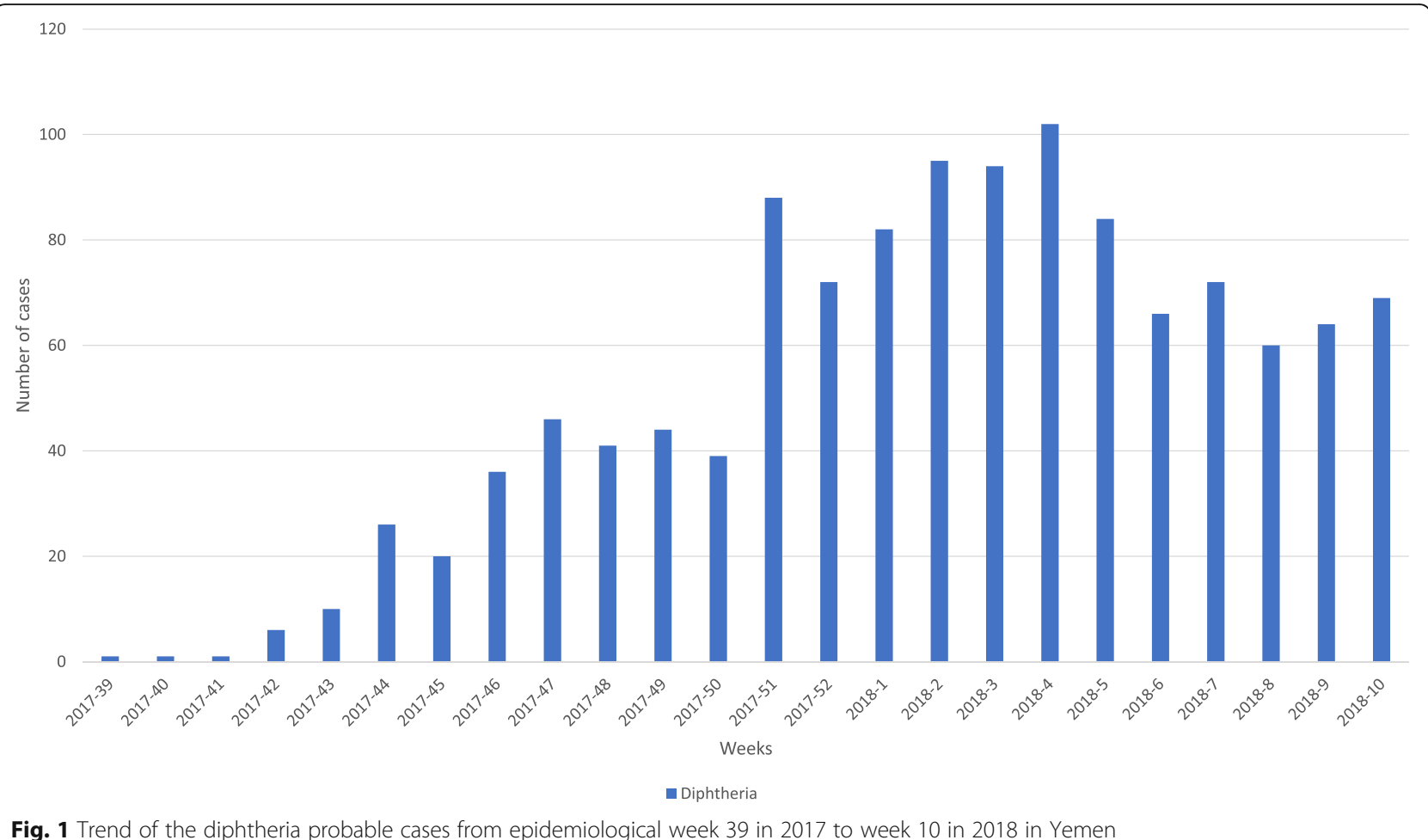

risk of a diphtheria outbreak significantly increases by 11 -fold if the district is currently experiencing armed conflict. This supports findings from another study on this topic in Yemen [14].

There is no doubt that conflict affects the delivery of health services, since about half of the health facilities are currently not functioning in Yemen [32]. As one consequence, immunization coverage is severely affected by the ongoing conflict, which largely explains the current infectious disease outbreaks in the country. Despite much evidence on the role of immunization coverage to prevent infection [33], this study shows that in a district that does not experience conflict, immunization coverage has a minimal effect on diphtheria outbreaks. One potential explanation of this unexpected finding is the inaccuracy of coverage rates per district, since the national EPI uses the number of a total population from old census data of 2004 as denominators without considering the increasing population due to movements by internally displaced persons (IDPs) during the war. Moreover, the quality of information has likely been affected by the breakdown of national reporting mechanisms. Also, this unexpected finding might have occurred due to unmeasured, unknown confounders that were not included into the logistic regression model. Finally, the quality of the vaccines in use could be affected due to breakdowns in the cold chain.

Continuous population movement is one of the conflict-related factors that contributes to the rapid
Table 3 Distribution of diphtheria cases and deaths and corresponding CFRs by age, sex and vaccination status

\begin{tabular}{|c|c|c|c|c|c|}
\hline \multirow[t]{2}{*}{ Variable } & \multicolumn{2}{|c|}{ Reported cases } & \multicolumn{2}{|l|}{ Deaths } & \multirow{2}{*}{$\begin{array}{l}\text { CFR } \\
\text { Percent }\end{array}$} \\
\hline & Frequency & Percent & Frequency & Percent & \\
\hline \multicolumn{6}{|l|}{ Sex } \\
\hline Male & 673 & 52 & 37 & 51 & 5.5 \\
\hline Female & 621 & 48 & 36 & 49 & 5.8 \\
\hline \multicolumn{6}{|l|}{ Age groups } \\
\hline $0-4$ years & 259 & 20 & 29 & 40 & 11 \\
\hline $5-9$ years & 324 & 25 & 21 & 29 & 6 \\
\hline $10-14$ years & 259 & 20 & 13 & 18 & 5 \\
\hline $15-24$ years & 194 & 15 & 7 & 10 & 7.7 \\
\hline $25-34$ years & 129 & 10 & 1 & 1 & 0.8 \\
\hline $35-50$ years & 91 & 7 & 1 & 1 & 1 \\
\hline$>50$ years & 39 & 3 & 1 & 1 & 2.5 \\
\hline \multicolumn{6}{|c|}{ Vaccination status } \\
\hline 0 dose & 595 & 46 & 50 & 69 & 8.4 \\
\hline 1 dose & 26 & 2 & 2 & 3 & 7.7 \\
\hline 2 doses & 78 & 6 & 4 & 5 & 5.1 \\
\hline 3 doses & 401 & 31 & 12 & 16 & 2.9 \\
\hline Unknown & 194 & 15 & 5 & 7 & 2.6 \\
\hline
\end{tabular}


Table 4 Bivariate logistic regression results for number of immunized children and conflict

\begin{tabular}{llll}
\hline Variable & Odds ratio $(\mathrm{OR})$ & $P$-value & $95 \% \mathrm{Cl}$ \\
\hline Number of immunized children & $1.02^{* * *}$ & 0.001 & $1.01-1.03$ \\
Conflict in past year & $0.59^{*}$ & 0.06 & $0.33-1.04$ \\
Ongoing conflict & $1.89^{* * *}$ & 0.01 & $1.20-2.99$ \\
$\begin{array}{l}\text { Number of immunized children } \\
\text { in areas with past conflict }\end{array}$ & $0.99^{* *}$ & 0.16 & $0.99-1.00$ \\
$\begin{array}{l}\text { Number of immunized children } \\
\text { in areas with ongoing conflict }\end{array}$ & $1.01^{* *}$ & 0.001 & $1.00-1.02$ \\
\hline
\end{tabular}

$N=333$ Significance: * $10 \%$ level; ** $5 \%$ level; *** $1 \%$ level.

spread of infectious diseases. Unfortunately, in a domestic armed conflict, individuals are forced to leave their homes and become IDPs within the country or take refuge outside the country [34]. IDPs and host communities become more susceptible to many infectious diseases due to multiple factors such as unplanned overcrowding, hygiene problems, lack of health services, and the introduction of new infectious agents. IDPs in Yemen may thus be an important contributing factor for the diphtheria outbreak. For example, this may explain the serious situation in the Ibb governorate, which has a very large number of the IDPs in Yemen [35].

In addition to the impact of the current war that has destroyed the country's infrastructure and deprived many people of the most basic services, the problem of IDPs and low immunization coverage, there are many additional factors that may have contributed to the emergence of epidemic diseases in Yemen over the past years. These include already existing poverty and malnutrition [36, 37]. Undernutrition has already been a huge public health problem in Yemen and contributes to the high mortality associated with infectious diseases, especially among children [38]. Approximately 2.2 million children in Yemen are acutely malnourished and 462,000 out of them suffer from severe acute malnutrition [39].

This study has some limitations. There were and still are challenges to obtain reliable data from Yemen, for example with regard to the distribution of IDPs by district. Another major limitation is related to our

Table 5 Multivariate logistic regression results for immunization and conflict

\begin{tabular}{llll}
\hline Variable & OR & $P$-value & $95 \% \mathrm{Cl}$ \\
\hline Number of immunized children & 1.04 & 0.002 & $1.01-1.058$ \\
Conflict in past year & 3.25 & 0.45 & $0.16-67.70$ \\
Ongoing conflict & 11.21 & 0.03 & $1.29-97.69$ \\
$\begin{array}{l}\text { Number of immunized children } \\
\text { in areas with past conflict }\end{array}$ & 0.98 & 0.32 & $0.95-1.02$ \\
$\begin{array}{l}\text { Number of immunized children } \\
\text { in areas with ongoing conflict }\end{array}$ & 0.98 & 0.13 & $0.95-1.01$ \\
Constant & 0.05 & 0.003 & $0.01-0.35$ \\
\hline
\end{tabular}

secondary analysis using existing poor quality data, e.g., old population counts for calculating the EPI coverage. Finally, the Yemeni health authorities have depended on patients or relatives to recall information regarding the vaccination status of cases in the daily diphtheria reports, which has a high probability of recall bias.

\section{Conclusion}

We conclude that the conflict is continuously devastating the health system in Yemen with serious consequences on morbidity and mortality. While emergency immunization campaigns are crucial interventions in the current situation to control and prevent infectious disease outbreaks, in the long-term, Yemen needs peace and the re-establishment of functioning health services within a frame of universal health coverage.

\section{Abbreviations}

DPT1: Diphtheria/pertussis/tetanus 1; eDEWS: Electronic Disease Early Warning System; EPI: Expanded Program on Immunization; IDPs: Internally displaced persons; MOPHP: Ministry of Public Health and Population; OR: Odd Ratio; WHO: World Health Organization

\section{Acknowledgements}

We express our gratitude to staff of the Ministry of Health and WHO in Yemen for their continuous efforts supporting the surveillance system and providing data. We thank Dr. Eshraq Al-Falahi from WHO Yemen, and Dr. Asma Dureab from SAWT foundation in Yemen for their valuable support and feedback. We acknowledge the financial support of Deutsche Forschungsgemeinschaft within the Open Access Publishing funding program and the Baden- Württemberg Ministry of Science, Research and the Arts and Ruprecht-Karls-Universität Heidelberg.

Funding

There was no fund contribution allocated for this study.

\section{Availability of data and materials}

The date was obtained from the published daily diphtheria surveillance reports (Oct 2017-March 2018), the daily reports were sent by Ministry of Health via email. The 2017 annual immunization coverage reports of 333 Yemeni districts was obtained from the EPI program in the Ministry of Health.

\section{Authors' contributions}

FD: the principle investigator, data analysis and wrote the manuscript. Ol: contributed in writing the second draft of the manuscript. MA: Participate in data collection and analysis. NK: analyzed and interpreted the results of the logistic regression. JK: contributed in data analysis and revision of the manuscript based on the reviewers' comments. OM: major contributor in writing the manuscript, review and check the analysis. AJ: the main supervisor and contributed in the manuscript design and review. All authors read and approved the final manuscript.

Ethics approval and consent to participate

Not applicable

Consent for publication

Not applicable

Competing interests

The authors declare that they have no competing interests.

\section{Publisher's Note}

Springer Nature remains neutral with regard to jurisdictional claims in published maps and institutional affiliations. 


\section{Author details}

Heidelberg Institute of Global Health, Hospital University- Heidelberg, Heidelberg, Germany. ${ }^{2}$ World Health Organization, WHO, Yemen Country Office, Sana'a, Yemen. ${ }^{3}$ University for Development Studies, Tamale, Ghana. ${ }^{4}$ Institute of Medical Biometry and Informatics, Heidelberg University, Heidelberg, Germany.

Received: 20 September 2018 Accepted: 7 May 2019

Published online: 22 May 2019

\section{References}

1. WHO. Diphtheria Geneva: World Health Organization 2018 [Available from: http://www.who.int/immunization/monitoring surveillance/burden/ diphtheria/en/. Accessed 18 Mar 2018.

2. Vitek C, Wenger J. Diphtheria. Bull World Health Organ. 1998;76(Suppl 2): 129-30.

3. M Lo Bruce. Diphtheria: Medscape 2017 [Available from: https://emedicine medscape.com/article/782051-overview. Accessed 18 Mar 2018.

4. Vitek CR. Diphtheria. Curr Top Microbiol Immunol. 2006;304:71-94.

5. Vitek CR, Wharton M. Diphtheria in the former Soviet Union: reemergence of a pandemic disease. Emerg Infect Dis. 1998;4(4):539-50.

6. Clarke K. Reveiw of the epidemiological of Diphtheria - 2000-2016. US centers for diseases control and prevention; 2017.

7. WHO. Diphtheria - Cox's Bazar in Bangladesh Geneva: World Health Organization; 2017. Available from: http://www.who.int/csr/don/13december-2017-diphtheria-bangladesh/en/. Accessed 18 Mar 2018.

8. European Centre for Disease Prevention and Control. Annual Epidemiological Report - Diphtheria. [Internet] Stockholm: ECDC; 2016. Available from: https://ecdc.europa.eu/en/publications-data/diphtheriaannual-epidemiological-report-2016-2014-data\#copy-to-clipboard. Accessed 18 Mar 2018

9. WHO, MOPH\&P. Weekly Epidemiological Bulletin. Epi week 32, Volume 06. Yemen: Ministry of Health. Aug 2018;2018:06-12.

10. OCHA-Yemen. Humanitarian Needs Overview Yemen: UNOCHA. 2018.

11. WHO. Potential impact of conflict on health in Iraq Geneva World Health Organization 2003 [Available from: http://www.who.int/features/2003/iraq/ briefings/iraq_briefing_note/en/. Accessed 24 Mar 2018.

12. Camacho A, Bouhenia M, Alyusfi R, Alkohlani A, Naji MAM, de Radigues X, et al. Cholera epidemic in Yemen, 2016-18: an analysis of surveillance data. Lancet Glob Health. 2018;6(6):e680-e90.

13. Gormley M. Untangling the causes of the 2016-18 cholera epidemic in Yemen. Lancet Glob Health. 2018;6(6):e600-e1.

14. Dureab F, Shibib K, Al-Yousufi R, Jahn A. Yemen: cholera outbreak and the ongoing armed conflict. J Infect Dev Countr. 2018;12(5):397-403.

15. Hadden RL. The geology of Yemen: an annotated bibliography of Yemen's geology, geography and earth science. Alexandria, Virginia: US Army Corps of Engineers, Army Geospatial Center; 2012. p. 385.

16. UNDP. Human Development Report 2016,Human Development for Everyone. New York, the USA; 2016. Contract No.: ISSN: 0969-4501.

17. CIA. Middle East : YEMEN Internet: the Central Intelligence Agency'; 2016. Available from: https://www.cia.gov/library/publications/the-world-factbook/ geos/ym.html. Accessed 29 Mar 2018.

18. Hill G. Yemen's urban-rural divide and the ultra-localisation of the civil war. London: Middle East Centre, London school of economics and. Political Science. 2017.

19. ECHO. Humanitarian Aid and Civil Protection Factsheet. Yemen: European Commission; 2017 Jan. 2017.

20. National Health Accounts Team, Republic of Yemen, Partners for Health Reformplus. Yemen National Health Accounts: estimate for 2003. Yemen; 2006

21. MOPH\&P. Annual Statistical Health Report. Yemen: Ministry of Public Health and Population; 2014.

22. Giles Clarke. Humanitarian Needs Overview. Yemen: United Nations Office for the Coordination of Humanitarian Affairs; 2018 Dec 2017.

23. WHO MOPHP. Service availability and health facilities functionality in 16 governorates (health services and resources availability mapping system). World Health Organization Yemen country office and Ministery of public health and population; 2016

24. WHO. Reported official target population, number of doses administrered and official coverage Geneva: World Health Organization; 2018. Available from: www.who.int/immunization/monitoring_surveillance/data/en/. Accessed 18 Mar 2018
25. EPI-Yemen. Annual accomulative report of the Imunization coverage 2017. National Expanded program of Immunization2018.

26. WHO. WHO-recommended surveillance standard of diphtheria 2014 [Available from: http://www.who.int/immunization/monitoring_surveillance/ burden/vpd/surveillance_type/passive/diphtheria_standards/en/. Accessed 20 May 2018.

27. Greene HW. Econometric Analysis. 5th ed. Upper Saddle River, New Jersey: Pearson Education Inc; 2003.

28. Kuunibe N, Domanban PB. Demand for complementary and alternative medicine in Ghana. Int J Humanit Soc Sci. 2012;2:288-94

29. Sein C, Tiwari T, Macneil A, Wannemuehler K, Soulaphy C, Souliphone P, et al. Diphtheria outbreak in Lao People's Democratic Republic, 2012-2013. Vaccine. 2016:34(36):4321-6.

30. Rahman MR, Islam K. Massive diphtheria outbreak among Rohingya refugees: lessons learnt. J Travel Med. 2018.

31. Besa NC, Coldiron ME, Bakri A, Raji A, Nsuami MJ, Rousseau C, et al. Diphtheria outbreak with high mortality in northeastern Nigeria. Epidemiol Infect. 2014;142(4):797-802.

32. El Bcheraoui $C$, Jumaan $A O$, Collison ML, Daoud F, Mokdad AH. Health in Yemen: losing ground in war time. Glob Health. 2018;14(1):42.

33. Hinman AR, Orenstein WA, Schuchat A. Vaccine-preventable diseases, immunizations, and the epidemic intelligence service. Am J Epidemiol. 2011;174(11 Suppl):S16-22

34. Ramirez JB, Franco $\mathrm{H}$. The effect of conflict and displacement on the health of internally displaced people: the Colombian. Crisis Medical Journal of the University of Ottawa. 2016:6(2: Global Health):26-9.

35. Dureab F, Muller O, Jahn A. Resurgence of diphtheria in Yemen due to population movement. J Travel Med. 2018;25(1).

36. EHINZ. Household crowding New Zealand: University of New Zealand 2018 [Available from: http://www.ehinz.ac.nz/indicators/indoor-environment/ household-crowding/. Accessed 20 Dec. 2018.

37. Virtanen M, Terho K, Oksanen T, Kurvinen T, Pentti J, Routamaa M, et al. Patients with infectious diseases, overcrowding, and health in hospital staff. Arch Intern Med. 2011;171(14):1296-8

38. Franca TGD, Ishikawa LLW, Zorzella-Pezavento SFG, Chiuso-Minicucci F, da Cunha MLRS, Sartori A. Impact of malnutrition on immunity and infection. J Venom Anim Toxins. 2009:15(3):374-90.

39. UNICEF. Malnutrition amongst Children in Yemen at an All-Time High, Warns UNICEF New York2016 [Available from: https://www.unicefusa.org/ press/releases/malnutrition-amongst-children-yemen-all-time-high-warnsunicef/31545. Accessed 20 Dec. 2018

Ready to submit your research? Choose BMC and benefit from

- fast, convenient online submission

- thorough peer review by experienced researchers in your field

- rapid publication on acceptance

- support for research data, including large and complex data types

- gold Open Access which fosters wider collaboration and increased citations

- maximum visibility for your research: over $100 \mathrm{M}$ website views per year

At $\mathrm{BMC}$, research is always in progress.

Learn more biomedcentral.com/submission 